\title{
EXTRAHEPATIC BILIARY DUCTAL VARIATIONS AND ITS CLINICAL SIGNIFICANCE
}

\author{
M. Lakshmidevi1 ${ }^{1}$ M. Uday Mudeebihal' ${ }^{2}$ M. Mallikarjuna ${ }^{3}$, K. S. Hanumanthaiah ${ }^{4}$, Manjunath $K^{5}$, Akhila $S^{6}$
}

${ }^{1}$ Assistant Professor, Department of Anatomy, BMCRI, Bangalore.

${ }_{2}^{2}$ Associate Professor, Department of Surgery, RRMCH, Bangalore.

${ }^{3} H O D$ and Professor, Department of Anatomy, VIMS, Bellary.

${ }^{4}$ Professor, Department of Surgery, RRMCH, Bangalore.

${ }^{5}$ Assistant Professor, Department of Surgery, RRMCH, Bangalore.

${ }^{6}$ Assistant Professor, Department of Surgery, RRMCH, Bangalore.

ABSTRACT

\section{BACKGROUND}

Incidence of liver and Gallbladder diseases are significantly increasing in recent years. Cholecystectomy either by laparoscopic or open is the commonest surgical procedure performed by General surgeon. Liver Transplantation is emerging as one of the top most transplantation surgery as well. Variations in anatomy of Gallbladder, bile ducts and the arteries that supply them and liver are important to the surgeon, because failure to recognize them may lead to inadvertent ductal ligation, biliary leaks, haemobilia, haemorrhage and strictures after cholecystectomy and may complicate Liver transplantation surgeries. Recognition of these anomalies and normal variants may avoid diagnostic errors, aid in surgical planning and prevent inadvertent ductal injury.

\section{OBJECTIVES}

To study the variations in Extrahepatic Biliary Ductal system with its clinical significance.

\section{RESULTS AND CONCLUSION}

Extrahepatic biliary ductal system studying under various methods are established; many variations in this region and understanding of these variations is undoubtedly important for operating surgeons. Starting from open cholecystectomy or laparoscopic cholecystectomy to cadaveric liver harvesting to recent advances like "Living donor liver transplantation with duct-toduct anastomosis" (LDLT), grading of tumours like hilar cholangiocarcinoma requires definitive knowledge of the anatomy of the ductal and arterial system.

Hence, we believe this study is not only confined to anatomists, but definitely be a useful guideline for general and laparoscopic surgeons, oncosurgeons and to transplant surgeons.

\section{KEYWORDS}

Extrahepatic Biliary Ductal, Cholecystectomy, Variations, Congenital Anomalies, Living Donor Liver Transplantation, Bile Duct Injuries.

HOW TO CITE THIS ARTICLE: Lakshmidevi M, Mudeebihal MU, Mallikarjuna M, et al. Extrahepatic biliary ductal variations and its clinical significance. J. Evolution Med. Dent. Sci. 2016;5(30):1537-1541, DOI: 10.14260/jemds/2016/362

\section{INTRODUCTION}

Biliary system anomalies are common and are of variable clinical importance. An awareness of these variations in the biliary system is a potential factor in preventing ductal injury during surgery. 1

The first thing which shocked us is how common this gallbladder and liver disease really is. Each year over 500,000 people are admitted into hospitals for gallbladder disease. Two-thirds of them are treated surgically. In studies of people $60-90$ years of age, $60 \%$ of the women and $30-50 \%$ of men were found to have gallstones. ${ }^{2}$

Cholecystectomy is the most commonly performed surgical procedure in general surgery. However, the Bile Duct Injury (BDI) is a rare but one of the most dreaded complication and BDI usually encountered by inexperienced surgeons and who are not familiar with the anatomy.

Financial or Other, Competing Interest: None.

Submission 10-03-2016, Peer Review 23-03-2016,

Acceptance 25-03-2016, Published 13-04-2016.

Corresponding Author:

Dr. M. Lakshmidevi,

294, 10 ${ }^{\text {th }}$ Main, NGEF Layout,

Nrupathunga Nagar,

Nagarabhavi, Bangalore.

E-mail: lakshmi9806@gmail.com

DOI: $10.14260 /$ jemds $/ 2016 / 362$
Laparoscopic Cholecystectomy (LC) is the "gold standard" procedure and incidence rate of BDI by LC has been found to three times higher than the open cholecystectomy. Living related Donor Liver Transplantation (LDLT) has emerged as an alternative to cadaveric liver transplantation because of the shortage of available cadaveric livers and drastic increase in demand for transplantation. Preoperative assessment of potential liver donors is requiring hepatic vascular and biliary anatomy. In the adult, right hepatic lobe transplantation is usually the procedure of choice to provide adequate liver volume to the recipient. ${ }^{3}$

Variations in the anatomy of gallbladder, bile ducts and the arteries that supply them and liver are important to the surgeon, because failure to recognize them may lead to inadvertent ductal ligation, biliary leaks, haemobilia, haemorrhage and strictures after laparoscopic or open cholecystectomy and may complicate surgeries such as liver transplantation.

Congenital anomalies of extrahepatic biliary tree have long been recognized, but are rare and may be of clinical importance, because they may provide surgeons with unusual surprises during surgeries. Recognition of these entities as anomalies and normal variants may avoid diagnostic errors, aid in surgical planning and prevent inadvertent ductal injury. ${ }^{4}$ 


\section{Normal Anatomy of the Extrahepatic Biliary Apparatus}

Fig. 1.

Normal anatomy of biliary tree will help in understanding and identifying group of anomalies. Extrahepatic biliary system consists of,

1. Common hepatic duct formed by the junction of Right and Left hepatic ducts.

2. The Gall Bladder, reservoir of bile.

3. Cystic duct of Gall Bladder.

4. Bile duct formed by the junction of Common Hepatic duct and Cystic duct.

\section{Hepatic Duct (HD)}

The Right and Left hepatic ducts (RHD and LHD) emerge from the right and left lobes of Liver in the porta hepatis. After short course, hepatic ducts unite to form Common Hepatic Duct (CHD). CHD is about $1 \frac{1}{2}$ inches ( $4 \mathrm{cms}$ ) long and $4 \mathrm{~mm}$ in calibre, descends within the free margin of lesser omentum and joined on the right side by the Cystic Duct (CD) from the Gall Bladder to form the Common Bile Duct (CBD).

\section{Gall Bladder (GB)}

Gall Bladder is a pyriform shaped sac lying on the under surface of the liver and has a capacity of about 30-50 mL and stores bile, which it concentrates by absorbing water. Gall Bladder is divided into the fundus, body and neck. Neck becomes continuous with Cystic duct, which turns into the lesser omentum to join the Common hepatic duct.

\section{Cystic Duct (CD)}

Cystic duct is about $3.8 \mathrm{cms}$ long and 2 to $3 \mathrm{~mm}$ in calibre, connects the neck of Gall Bladder to the right side of common Hepatic Duct to form the Bile Duct. It is related behind to portal vein, medially to common hepatic duct and laterally to cystic artery.

\section{Bile Duct (BD)}

The bile duct (Common Bile Duct) is about 3 inches $(8 \mathrm{cms})$ long and $6 \mathrm{~mm}$ in calibre. In the first part (Supraduodenal) of its course, it lies in the right free margin of the lesser omentum in front of opening into lesser sac. Here, it lies in front of right margin of portal vein and to the right side of the Hepatic Artery. In the second part (Retroduodenal) of its course, it is situated behind the first part of the duodenum to the right of gastroduodenal artery. In the third part (Infraduodenal) of its course, it lies in a groove on the posterior surface of the head of the Pancreas. Here, the bile duct comes in contact of the main pancreatic duct. The bile duct ends below by piercing the medial wall of second part of duodenum about halfway down its length, it is usually joined by the main pancreatic duct and together they open into a small ampulla in the duodenal wall called ampulla of vater.

\section{Blood Supply}

Gall bladder is supplied by cystic artery, which is a single branch of the right hepatic artery. Cystic artery is usually located parallel and medial to the cystic duct, but its course varies with its origin. Cystic artery divided into superficial and deep branches before entering the gall bladder.

Blood supply to the extrahepatic biliary tree originated distally from the gastroduodenal, retroduodenal and posterior superior pancreato-duodenal arteries and proximally from the right hepatic and cystic arteries. These arteries supply the common bile duct and common hepatic duct through branches running parallel to the duct in the 3 and 9 clock positions.

\section{Venous Drainage}

Small veins from the biliary tract drains to the portal vein and enter the liver. Venous return is by multiple small veins in the gall bladder bed into the substance of the liver and so into the hepatic veins. Cystic veins do not accompany cystic artery.

\section{Lymphatic Drainage}

Lymphatic channels from the GB drains to nodes in the porta hepatis to the cystic node (node of Lund) to a node situated at the anterior boundary of the epiploic foramen. From these nodes, lymph passes to the coeliac group of preaortic nodes.

\section{Nerve Supply of the Biliary Tract}

Parasympathetic fibers mainly from the hepatic branch of the anterior vagal trunk stimulate contraction of the GB and relax the ampullary sphincter. Sympathetic fibers from cell bodies in the celiac ganglia inhibit contraction, but the hormonal control of GB activity is much more important than the neural.

\section{METHODS}

- Study materials consisted of 50 adult specimens.

- 10 specimens from dissection room, Department of Anatomy.

- 40 Enbloc Post Mortem Specimens from Department of Forensic Medicine.

\section{Formation of Common Hepatic Duct}

Site of union of right and left hepatic ducts.

a. Extrahepatic union of right and left hepatic ducts: (Fig. 2)

The right and left hepatic ducts united outside the porta hepatis.

b. Intrahepatic union of right and left hepatic ducts: (Fig. 3)

Right and left ducts united intrahepatically and common hepatic duct emerged from the substance of liver at porta hepatis.

Table reflect the comparison of our study with others. On comparing the above studies extrahepatic union of right and left hepatic ducts is found to be more common than intrahepatic union (Table 1).

Types of Union of Cystic Duct with Common Hepatic Duct Three types of union of cystic duct with common hepatic duct.

\section{Angular Type}

CD makes an acute angle to join with the CHD (Fig. 4).

In all the specimens, cystic duct united at the right side of common hepatic duct. In one case, cystic duct was seen at the left side of common hepatic duct and unites with common hepatic duct at its left side without any situs inversus.

\section{Parallel Type}

CD runs parallel with CHD for a varying distance before it unites with CHD; 10 specimens (20\%) were observed to be parallel type of union in this study (Fig. 5).

\section{Spiral Type}

CD makes a spiral course before joining with CHD either on antero-lateral or postero-lateral side of it. 
This agrees with Eisendrath's study except in spiral type of union. On comparing the above studies, the most common type of union of cystic duct with common hepatic duct is angular type (Table 2).

\section{Surgical Importance}

In parallel type of union, both the cystic duct and common hepatic duct are closely bound together and their separation becomes difficult. Moreover, in parallel type two ducts may closely adherent to each other, so it is difficult to put a clamp without injuring common hepatic duct. In addition to this, "cystic duct remnant syndrome" may occur in parallel type of union with various sequelae leading to post cholecystectomy symptoms being the site of chronic inflammation, lithiasis or neuroma formation. ${ }^{5}$

Johnston and Anson reported that it is obvious that both parallel and spiral type of union presents difficulty in surgery. ${ }^{6}$

\section{Level of Termination of Cystic Duct}

The Levels of Termination of Cystic Duct with Common Hepatic Ducts are,

1. High level.

2. Low level.

3. Normal level.

In high level of union cystic duct unites with common hepatic duct close to the bifurcation of right and left hepatic ducts. In this level the common hepatic duct length is very small than its average and common bile duct length is more.

In low level of termination, cystic duct unites with common hepatic duct further away from the bifurcation to make common hepatic duct longer than common bile duct.

In normal level of union, common bile duct is longer than common hepatic duct.

Hossein Mahour, study on 100 specimens, described about the height of termination of cystic duct. In that, in $80 \%$ of cases cystic duct runs obliquely to join common hepatic duct. This type gives a short hepaticus and long common bile duct; this type was observed to be more common. In $18 \%$ of cases low level of union and in $1.5 \%$ of cases high level of union was noted.

In the present study, normal level of union of cystic duct with common hepatic duct was visualized in $80 \%$ (40) of cases, high level of union of cystic duct with common hepatic duct was observed in $20 \%$ (10) of cases and low level of union was not noted in any dissection specimens. Hence, the present study coincides with that of Hossein Mahour in terms of normal level of union, but not regarding high and of low level of union.

The level of union, high or low insertion of cystic duct carries significant because of the potential for injury in biliary surgery. ${ }^{7}$ (Table 3 ).

\section{Course and Arrangement of Structures in Hepatoduodenal Ligament}

Arrangements of structures in hepatoduodenal ligament described by Hollinshead. ${ }^{8}$ is CBD lies anterior and to the right, hepatic artery lies anterior just to the left of common bile duct. The portal vein lies behind the duct and artery usually larger and to the left of the duct.

He also mentioned that not more than $1 / 3$ of liver shows the so called normal arrangement, remaining $2 / 3$ presents with variation from this and many of them carries direct surgical importance.

In present study the arrangement of structures was observed to be the same as mentioned by Hollingshead, except in $2.5 \%$ of cases in which the common bile duct lies anterior and to the right in the actual edge of hepatoduodenal ligament. The hepatic artery lies anterior just to the left of common bile duct. The portal vein lies behind the duct and artery and to the right of duct.

The Surgical Importance of the structures in hepatoduodenal ligament was given by McGregor. ${ }^{9} \mathrm{He}$ described "Pringle's Manoeuvre." The vessels in the free border of the lesser omentum may be controlled by compression between the thumb and index finger of the left hand. This measure is an emergency one, which may be useful in cases of injury to one of the large vessels in the area or in hepatic injuries. It is safe for 30 minutes if BP is normal. ${ }^{10}$

\section{Variations in Ductal System}

The variations in ductal system can be discussed under the following headings.

1. Presence of accessory hepatic or cystic ducts.

2. Mode of termination of accessory hepatic or cystic ducts.

\section{Presence of Accessory Hepatic or Cystic Ducts}

Schachner. ${ }^{11}$ noted, double cystic duct in 2 cases, absence of common bile duct in 1 case.

Present study, accessory cystic duct (Double cystic duct) was noted in 2 specimens and in 1 specimen, the cystic duct is long opening directly into the 2nd part of duodenum. Hence, our observations correlated with that of Schachner.

Flint. ${ }^{12}$ described about $14.5 \%$ accessory bile ducts and all were accessory right hepatic ducts.

Lurje. ${ }^{13}$ reported $2.8 \%$ of accessory ducts emerged from right side of liver. In this study, we observed in $16 \%$ accessory hepatic ducts issuing from the right lobe of liver.

On comparing the above studies, the present study coincides with that of Flint and Lurje regarding the presence of accessory right hepatic duct.

\section{Mode of Termination of Duct}

Flint from 200 specimens classified 29 accessory bile ducts on the basis of termination as,

\begin{tabular}{|c|c|c|}
\hline & $\begin{array}{c}\text { Flint } \\
\text { Study }\end{array}$ & $\begin{array}{c}\text { Present } \\
\text { Study }\end{array}$ \\
\hline $\begin{array}{c}\text { Junction occurs in upper 1/2 of } \\
\text { common hepatic duct (or) in right } \\
\text { hepatic duct - High Union }\end{array}$ & $4.5 \%$ & $4 \%$ \\
\hline $\begin{array}{c}\text { Junction occurs in lower } 1 / 2 \text { of } \\
\text { common hepatic duct }\end{array}$ & $4.5 \%$ & $4 \%$ \\
\hline $\begin{array}{c}\text { Junction at the union of cystic and } \\
\text { common hepatic duct }\end{array}$ & $5 \%$ & Nil \\
\hline
\end{tabular}

The present study coincides with the above study except in termination at the union of cystic and common hepatic duct.

\section{Clinical Importance}

Injury to any part of the extrahepatic biliary tree may result in bile leakage, which leads to biliary peritonitis. 


\section{Calot's Triangle}

In the anatomical basis of clinical practice. ${ }^{14}$ it is mentioned that the near triangular space formed between the cystic duct, common hepatic duct and inferior surface of segment $V$ of liver is commonly referred to as Calot's triangle. This space usually contains cystic artery, one or two cystic veins.

In the present study, the boundaries of the Calot's triangle was defined $98 \%$ of cases and in $2 \%$ of cases the boundaries were altered as cystic duct on the left side, common hepatic duct on the right side and hilum of liver above without any situs inversus.

\section{Clinical Importance}

To avoid misidentification of ducts, identification of cystic duct, cystic artery and the structures to be divided in cholecystectomy both open or laparoscopic cholecystectomy, Calot's triangle must be dissected and studied. Moreover, failure to define the normal anatomy and difficult to dissect the Calot's triangle results in increased incidence of iatrogenic injury to biliary and portal structures. ${ }^{15}$

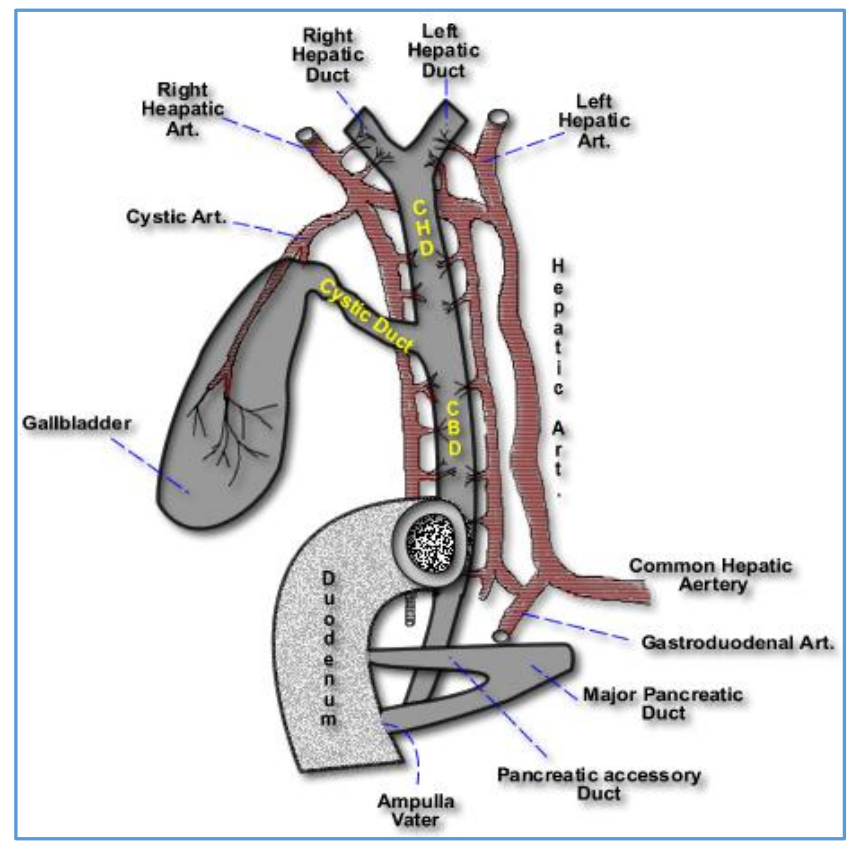

Fig. 1
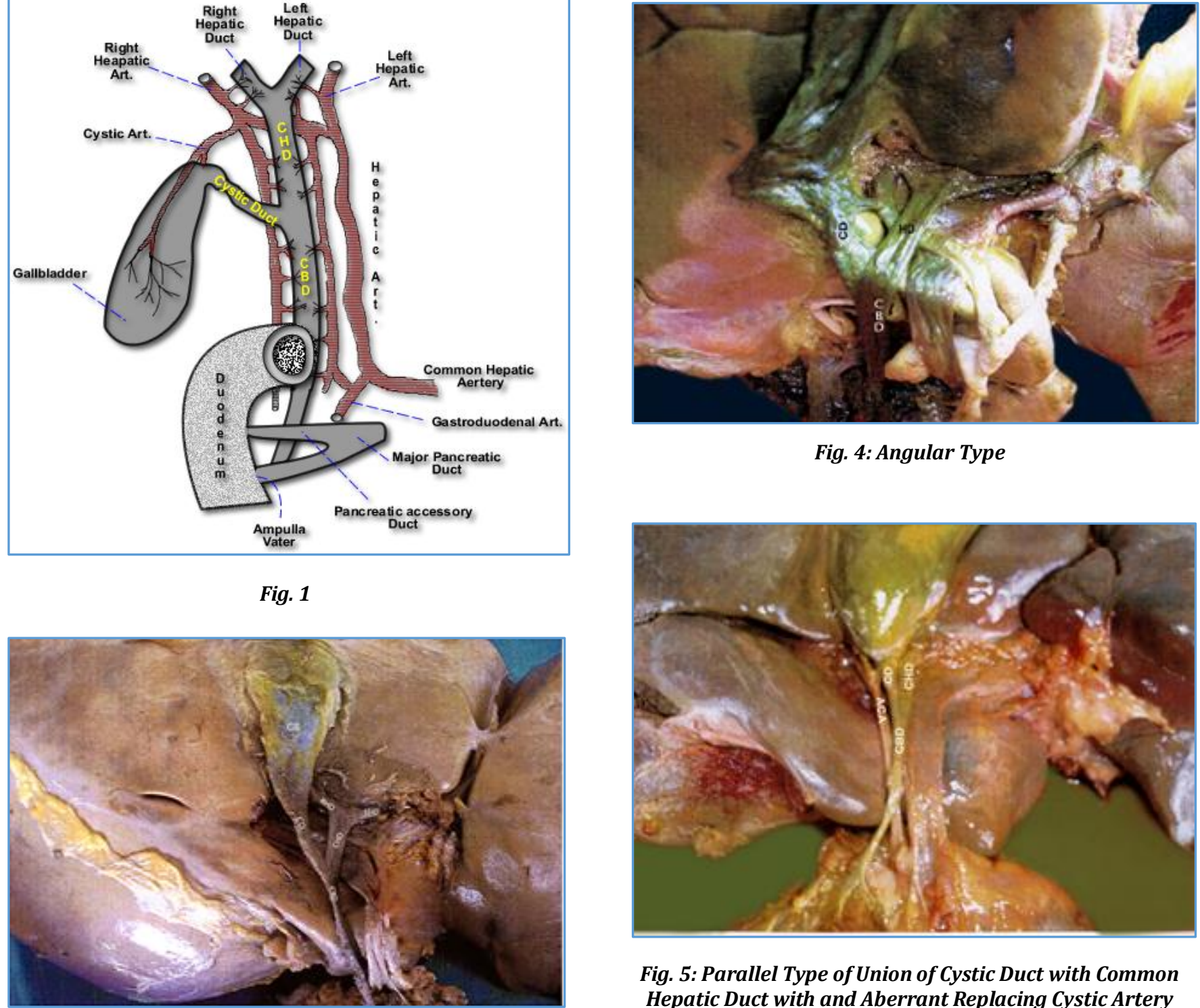

Fig. 4: Angular Type

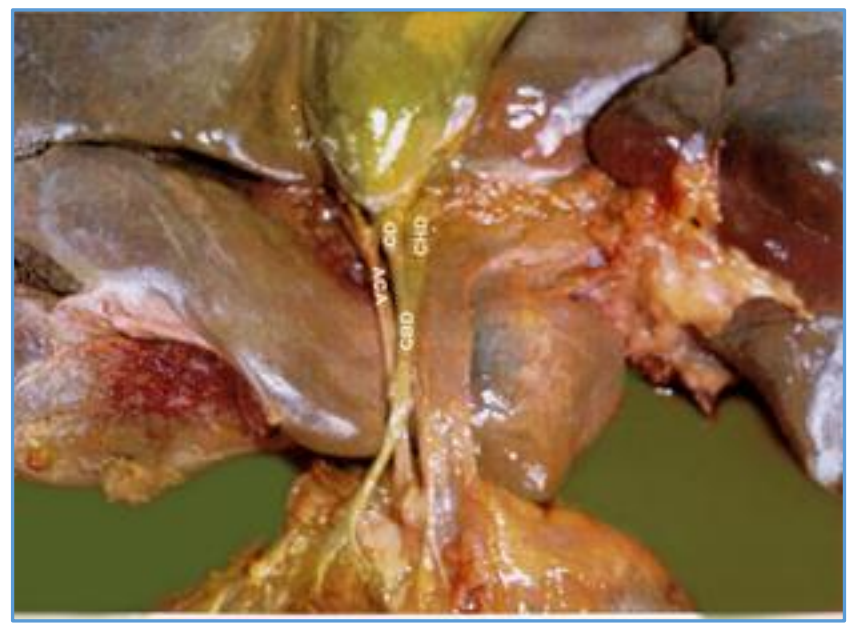

Fig. 5: Parallel Type of Union of Cystic Duct with Common Hepatic Duct with and Aberrant Replacing Cystic Artery

Fig. 2: Extrahepatic Union of Right and Left Hepatic Ducts 


\begin{tabular}{|c|c|c|c|c|c|}
\hline Authors & $\begin{array}{c}\text { Brewer et al. } \\
(\mathbf{1 9 0 0 )}\end{array}$ & $\begin{array}{c}\text { Rugg (1908) } \\
\text { et al. }\end{array}$ & $\begin{array}{c}\text { Eisendrath } \\
\text { (1918) et al. }\end{array}$ & $\begin{array}{c}\text { Thompson } \\
\text { (1933) et al. }\end{array}$ & $\begin{array}{c}\text { Present } \\
\text { Study }\end{array}$ \\
\hline Intrahepatic & 100 & 79 & 100 & 90 & 70 \\
\hline Extrahepatic & 0 & 21 & 0 & 10 & 30 \\
\hline \multicolumn{7}{|c|}{ Table 1 } \\
\hline
\end{tabular}

\begin{tabular}{|c|c|c|c|}
\hline Authors & Angular & Parallel & Spiral \\
\hline Rugg (1908) & $35 \%$ & $20 \%$ & $45 \%$ \\
\hline Eisendrath (1918) & $75 \%$ & $17 \%$ & $8 \%$ \\
\hline Thompson (1933) & $90 \%$ & $6 \%$ & $4 \%$ \\
\hline A. Lurje (1937) & $46.9 \%$ & $30.9 \%$ & $22.2 \%$ \\
\hline Edward (1952) & $51.4 \%$ & $31.4 \%$ & $17.1 \%$ \\
\hline Present Study & $75 \%$ & $25 \%$ & $0 \%$ \\
\hline \multicolumn{4}{|c|}{ Table 2 } \\
\hline
\end{tabular}

\begin{tabular}{|c|c|c|c|}
\hline \multirow{2}{*}{ Study } & \multicolumn{3}{|c|}{ Level of Termination of Cystic Duct } \\
\cline { 2 - 4 } & Normal & High Level & Low Level \\
\hline Hossein Mahour & $80 \%$ & $15 \%$ & $18 \%$ \\
\hline Our Study & $80 \%$ & $20 \%$ & $0 \%$ \\
\hline \multicolumn{4}{|c|}{ Table 3 } \\
\hline
\end{tabular}

\section{CONCLUSION}

Extrahepatic biliary system variations and its clinical significance is undoubtedly important for operating surgeons. Starting from open cholecystectomy or laparoscopic cholecystectomy to cadaveric liver harvesting to recent advances like "Living Donor Liver Transplantation with duct to duct anastomosis" (LDLT), grading of tumours like hilar cholangiocarcinoma, requires definitive knowledge of the anatomy of the ductal and arterial system.

Hence, we believe this study is not only confined to anatomists, but definitely be a useful guideline for general and laparoscopic surgeons, oncosurgeons and to transplant surgeons.

\section{REFERENCES}

1. Brandt CP, Eckhauser ML. Rare bile duct anomalies a case report and implications for laparoscopic cholecystectomy. Surg endosc 1994;8(4):329-331.

2. Gupta S. Incidence of cholelithiasis in India. International surgery 1977;62(3):169-71.

3. Macdonald DB, Haider MA, Khalili K, et al. Relationship between vascular and biliary liver anatomy in living liver donors. American Journal of Radiology 2005;185(1):247-52.
4. Ruge Ernst. Beitraege zur chirurgischen anatomie der grossen gallenwege. Arch F kiln Chir 1908;7:47-78.

5. Gene L Colborn. Skandalakis' surgical anatomy: the embryologic and anatomic basis of modern surgery. PMP 2004;2:1720.

6. Edward V Johnston, Barry J Anson. Variations in the formation and vascular relationship of the bile ducts. Surg Gynecol Obstet 1952;94(6):669-686.

7. Grainger RG, Allison DJ. Grainger and allison's diagnostic radiology: a text book of medical imaging. Churchill Livingstone 1997;3:2698.

8. Thompson JM. Arteries in the hepatic pedicle, study in statistical human anatomy. Univ Califo Pub Anatomy 1933;158:555.

9. Alexander Lee McGregor. A synopsis of surgical anatomy Editors: briston-johnwright and sons Ltd $1986 ; 12^{\text {th }}$ edition. ISBN: 9780723608011

10. Michael J Zinner, Stanley W Ashley. Maginot's abdominal operations $11^{\text {th }}$ edition, 2007;205(6):3-4.

11. Schanchner A. Anomalies of the gall-bladder and bilepassages. Ann Surg 1916;64:419-33.

12. Flint ER. Abnormalities in anatomy of bile tract. British Journal of surgery 1922-23;10:509-519.

13. Lurje MD. The topography of the extra hepatic biliary passages: with reference to dangers of surgical technic. Ann Surg 1937;105(2):161-168.

14. Gray's Anatomy. The anatomical basis of clinical practice. Editors: Susanstandring 2008;40 th edition.

15. Way LW, Stewart L, Gantert W. Causes and prevention of laparoscopic bile duct injuries: analysis of 252 cases from a human factors and cognitive psychology perspective. Ann Surg 2003;237(4):460-9. http://www.ncbi.nlm:nib:gov/entrez/query.fcgi?cmd Retrieve and $\mathrm{db}=$ pub med $\&$ dopt $=$ Abstract and list. 